International Journal of Linguistics, Literature and Translation

ISSN: 2617-0299 (Online); ISSN: 2708-0099 (Print)

DOI: $10.32996 / \mathrm{jjllt}$

Journal Homepage: www.al-kindipublisher.com/index.php/ijltt

\title{
Saudi EFL Students' Perceptions of Online English Achievement Exams in the Era of COVID-19
}

\author{
Ajwaad Aljohani ${ }^{1} 8$ (D), Mashael Aloreafy 28 (D), Sarah Alzaidi ${ }^{3} 8$ (D) and Zilal Meccawy ${ }^{4} 8$ (D) $\square$ \\ ${ }^{13} \mathrm{MA}$ Student, TESOL, English Language Institute, King Abdulaziz University, Jeddah, Saudi Arabia \\ ${ }^{2}$ Teaching Assistant, ELI, University of Jeddah \& MA in TESOL student, English Language Institute, King Abdulaziz University, \\ Jeddah, Saudi Arabia \\ ${ }^{4}$ Assistant Professor, English Language Institute, King Abdulaziz University, Jeddah, Saudi Arabia
}

$\square$ Corresponding Author: Zilal Meccawy, E-mail: zmeccawy@kau.edu.sa

\section{ARTICLE INFORMATION}

Received: April 05, 2021

Accepted: May 13, 2021

Volume: 4

Issue: 5

DOI: $10.32996 /$ ijllt.2021.4.5.11

\section{KEYWORDS}

Availability and accessibility; EFL; exam instruction; mode of delivery; online achievement exam; Saudi Arabia; students' perceptions

\section{ABSTRACT}

Due to the COVID-19 pandemic, assessment and testing processes have been shifted to an online environment. Therefore, this unexpected shift requires more recent research in the field of online assessment. Based on this requirement, the present research aimed to explore female EFL students' perceptions of an online English achievement exam by focusing on these dimensions: availability and accessibility, instructions, and mode of delivery. The participants were preparatory year students at the English Language Institute (ELI) at the University of Jeddah. To serve the research aim, the research used a mixed-methods approach. Students $(n=49)$ participated in the quantitative phase by answering an online survey and 2 students were interviewed in the qualitative phase. The quantitative data revealed that the students had a positive perception of the online exam availability, accessibility, instruction, and mode of delivery. More particularly, the qualitative data explained that the clear online exam instructions and suitable mode of delivery have significantly improved these positive perceptions.

\section{Introduction}

After the outbreak of the COVID-19 pandemic in the spring of 2020, the Saudi government opted to shift to online learning to ensure learning continuity. As this unexpected shift to online learning continues, universities are in the midst of developing advanced features for online assessments (Butler-Henderson \& Crawford, 2020). Online assessments are designed as alternative tools to face-to-face exams; consequently, implementing an assessment process that uses electronic versions of exams requires significant preparation (Sarrayrih \& Ilyas, 2013). Due to this change, students may have different perceptions towards online examination as compared to face-to-face exams; therefore, this paper explores EFL students' perceptions of an online English achievement exam at the University of Jeddah in Saudi Arabia. Although a systematic study examined students' perceptions of online assessments (Butler-Henderson \& Crawford, 2020), the sudden shift to online learning in the era of COVID-19 justifies further exploring students' perceptions of online exams as an achievement assessment. As all universities in Saudi Arabia were suspended due to the spread of the COVID-19, all assessments were delivered online (Layali \& Al-Shlowiy, 2020). Accordingly, this study aims to contribute to the growing research on the online testing environment by exploring students' experiences. The main purpose of this study is to develop an understanding of EFL students' perceptions of online English achievement exams in Saudi Arabia. For this purpose, the study attempts to address the following question: What are EFL students' perceptions of the online English achievement exam in Saudi Arabia?

\section{Literature Review}

The primary objective of this review is to explore students' perceptions on the availability, accessibility, clarity of instructions, and mode of delivery for online English Achievement exams.

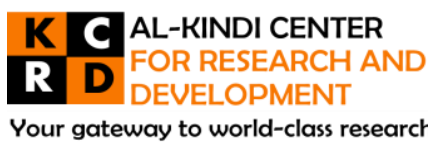

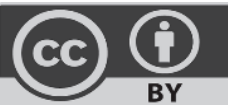

Published by Al-Kindi Center for Research and Development, London, United Kingdom. Copyright (c) the author(s). This open access article is distributed under a Creative Commons Attribution (CC-BY) 4.0 license 


\subsection{Availability and Accessibility}

Availability and accessibility are two of the greatest factors that should be carefully considered in preparing for online exams (Rahim, 2020; Isbell \& Kremmel, 2020). Therefore, several concerns have been raised regarding these two concepts after the outbreak of COVID-19. Pearson and Koppi (2002) defined accessibility as the equality in an online educational experience that allows students to take part in learning in spite of their technical tools. In terms of availability, it is the availability of important technical support and tools at any time and place (Salmon, 2013). Examples include the availability and accessibility of internet speed, web connections, electronic devices, and financial costs associated. Despite the fact that students are more familiar with mobile devices (Alharbi \& Meccawy, 2020), most online exams do not operate via mobile devices. As a result, the shortcomings of online exams' operation flexibility can force students to buy new computer devices. This view is supported by Isbell and Kremmel (2020) who argued that the availability of personal computers is simply not affordable for some examinees. Indeed, the financial cost is considered a significant issue that is associated with online exams. Nowadays, due to the fact that the use of the internet is widely accessible in the 21st century, students prefer online examinations (Butler-Henderson \& Crawford, 2020). Indeed, a previous study found that $67 \%$ percent of students had a positive experience with online exams (Matthíasdottir \& Arnalds, 2016). However, Bisht, Jasola, and Bisht (2020) found that connecting to the internet is the most critical issue for students in online exams. Most online exams are only accessed if the user has an appropriate level of internet speed. For example, the online versions of the IELTS and TOFEL require users to have at least $2 \mathrm{MB}$ per second to upload the online exam (Isbell \& Kremmel, 2020). In fact, students who have access to the internet may face difficulty in terms of internet speed and good internet speed may not be available for all students during the online exam time. This is problematic because the availability of online testing is extensively limited to a fixed period of time (Stack et al., 2020). Moreover, high-speed internet can also affect the reliability of the online assessment; for instance, Yoshino et al., (2001) found that online video assessment that is conducted with high-speed internet yields more reliable results. This issue gives rise to numerous questions regarding the correlation between internet speed and online exam reliability. Therefore, it can be said that internet speed is not merely a technical requirement but a significant element that affects the exam's reliability. In order to solve the critical issue of speed, the International Test Commission (2006) recommended that test developers take into consideration that internet speed might differ due to the variety of geographical locations of the test takers. In other words, test developers need to design online exams that can work even with very low-speed connections. Collectively, these findings show that internet availability and accessibility of online assessments should be taken into consideration.

\subsection{Online Exam Instructions}

Completing online exams entails dealing with multiple technical tools and understanding the online exam's requirements. Consequently, students should be provided with a holistic picture of the myriad of instructions, which they may need to follow during the online exam. Online exam instructions refer to the rules for how the user should progress throughout the exam, e.g., the exam instructions of submitting the response for each item. This section explores some of the necessary instructions that can be presented to students before and during online exams. When designing online exams, instructors must clearly state the exam rules for students (Sewell et al., 2010). A previous study has shown that students complained about the lack of important rules at the beginning of online exams (Shraim, 2019). Shraim (2019) concluded that the lack of the clarity in online exam instructions increased students' anxiety. Therefore, Rahim (2020) suggested that exam providers should use multiple examples when explaining online exam procedures to students. Additionally, one of the specific instructions that should be given to test takers is specifying the browser that should be used to operate the online exam (International Test Commission, 2006). These detailed instructions should be delivered to students before the exam time in order to provide time for clarification. Regarding the instructions given during the exam time, Özden, Ertürk, and Sanli (2004) found that online exam takers mostly skip the help page, even though this page may include valuable information about exam instructions. Moreover, the researchers found that this page is often neglected because the instructions were not presented clearly enough. As a result, students may end up confused about what they should do during the exam.

\subsection{Mode of Delivery for Online Exams}

The mode of delivery of online exams, which is a factor of particular importance in such tests, refers to the methods used to display the instructions and questions to students (Yildiz \& Keengwe, 2016). In the case of online exams, the delivery mode is significant to content and technical quality (International Test Commission, 2006). According to Stack et al. (2020), the delivery mode in online exams is a pedagogical practice that should consider many aspects of technical quality, including the number of questions displayed per section, question types, number of attempts permitted, and time restriction. Therefore, the pedagogical practices related to delivery modes could have a huge impact on learners' digital literacy (DL). Mohammadyari and Singh (2015) defined digital literacy ( $\mathrm{DL}$ ) as "the ability to understand, analyze, assess, organize and evaluate information using digital technologies" (p.15). Regarding online exam delivery, Blackboard is mostly used as a testing tool in several universities, especially in Saudi Arabia, where it is considered an authorized educational learning management system LMS. Therefore, it is important to explore students' point of view in delivering the online exams via Blackboard testing systems for this study. Alshehri, Rutter, and Smith (2019) highlighted that online exam delivery is increasingly becoming a point of focus among test-takers, where their 
findings concluded that students' preferences regarding delivery features in Blackboard were for "information quality, navigation and learnability" (as cited in Layali \& Al-Shlowiy, 2020, p.99). Test takers' unfamiliarity or inexperience with certain delivery mode(s) in online exams could also affect their performance; therefore, students need to be trained to be familiar with various modes. For example, Brunfaut, Harding, and Battyb (2018) studied the effect of delivery mode on students' performance on a writing skill exam. The results appeared to highlight a positive correlation between test takers' familiarity with the mode of delivery and their writing performances. Thus, a more convenient online setting supported students' ability to demonstrate their writing skills, such as typing skills, while unfamiliar mode(s) could lower comprehension of the test's instructions and questions, leading to decreased test performances (as cited in Brunfaut, Harding, \& Battyb, 2018). Moreover, students should be provided with technical support during any online exam in order to ensure a proper mode of delivery. This view is supported by Frankl and Bitter (2012), who recommended that technical support should be made available to students during online testing in case of any difficulties.

\section{Methodology}

In this study, a mixed-methods approach was used to gain a better understanding of Saudi EFL students' perceptions of the online English achievement exam. Quantitative data were collected via an online questionnaire using SurveyMonkey, while qualitative data were collected via online interviews. The gathered data were analysed using SurveyMonkey and SPSS software (version 21).

\subsection{Participants and Context}

The participants were female EFL Preparatory Year students from Saudi Arabia. The students were studying English online via Blackboard Collaborate Ultra at the ELI at the University of Jeddah. The students were Arabic native language speakers and they were between 18-22 years of age. A convenience sampling strategy was chosen based on the accessibility of the students (Dornyei, 2007). A total of $49(n=49)$ students participated in the survey. All students were in the Science Track and their level of English language proficiency was B1, which is considered an intermediate level based on the Common European Framework Reference (CEFR). The participants had a compulsory online English achievement exam as a part of their English language course. The achievement exam can be defined as a test that measures students' skills and knowledge (Fulcher, 2010). The online English exam included 15 multiple-choice items that tested students' achievement in listening, reading, grammar and vocabulary skills and the duration of the exam was limited to 60 minutes. Students had the option to shift between the exam items. In the quantitative phase, all 49 participants completed the online survey. In the qualitative phase, two participants were interviewed.

\subsection{Instruments and Procedures (1) Questionnaire}

SurveyMonkey was the tool used to create and share the questionnaire via an active hyperlink, which was sent to the students' university email accounts. The online questionnaire consisted of three sections: the first section explained the purpose of the survey and informed consent to participate, while the following two sections presented the survey items. All items were closedended and asked students to respond using a five-point Likert scale from 1 (=strongly agree) to 5 (=strongly disagree). The questionnaire was translated into Arabic to make sure that the participants would have a clear understanding of the items. In addition, to validate the questionnaire items, the questionnaire was piloted with five participants. Also, two EFL university instructors were invited to review the questionnaire and add comments using the 'invite' tool on SurveyMonkey. After that, the items were modified according to their comments. At the end of the questionnaire, an item for providing contact information was added as a request for students to volunteer for the follow-up interview.

\section{(2) Interviews}

Two students consented via the online questionnaire to participate in the interview. The purpose of conducting interviews was to provide more insight into students' online English achievement exam experience and both interviews were conducted via an individual phone call. Before the interviews, the students were contacted via WhatsApp to specify a convenient time for the interview and an audio recorder was used to record the conversation during the interview after obtaining their approval via a SurveyMonkey form. Both interviews were semi-structured, took 10 minutes per participant and focused on exploring students' perceptions of their online English achievement exam. Therefore, the main question was: What do you think about the English achievement exam being online? After conducting the interviews, an online speech-to-text tool, Amber, was used to transcribe the interviews' recordings, the transcripts were analysed by following major patterns (Braun \& Clarke, 2006) and data from the interviews were highlighted and explored in the results.

The researchers have followed several ethical considerations. Before the start of the study, the researchers obtained an online data collection approval from the ELI at the University of Jeddah. Also, the students were asked to sign an acknowledgement form prior to the questionnaire and interview, where it guaranteed confidentiality and attained the participants' approval. Furthermore, the acknowledgement form stressed that students' participation was voluntary and that they can withdraw at any 
point without any consequences. Based on their approval, the interviews were recorded and to ensure the anonymity of the students, no personal data were obtained.

\section{Results and Discussion}

The items of the survey were tested using Cronbach's Alpha to ensure the reliability of the survey, where the analysis gave an acceptable average of 0.781 as according to Dornyei (2007), Cronbach Alpha's result should be above 0.60 score.

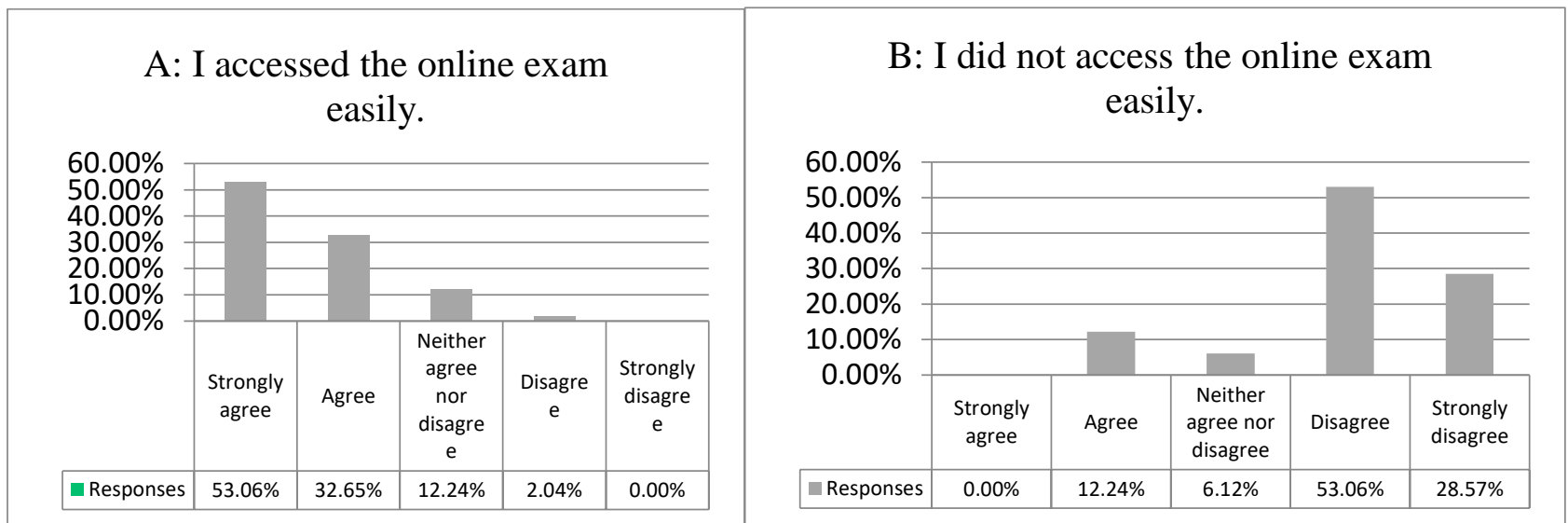

Figure 1. Accessibility of the Online Exam

In terms of accessibility, the first set of results demonstrates that the majority of students (85\%) accessed the online exam easily (see Figure 1A). Moreover, as shown in Figure 1,81.63\% of the students confirmed that they did not face any difficulty with the exam accessibility. Very few students expressed a contrary view, where only $12.24 \%$ of students felt that accessibility to the online exam was not easy (see Figure 1B). Overall, Figure 1 clearly shows that students have a positive experience towards online exam accessibility.

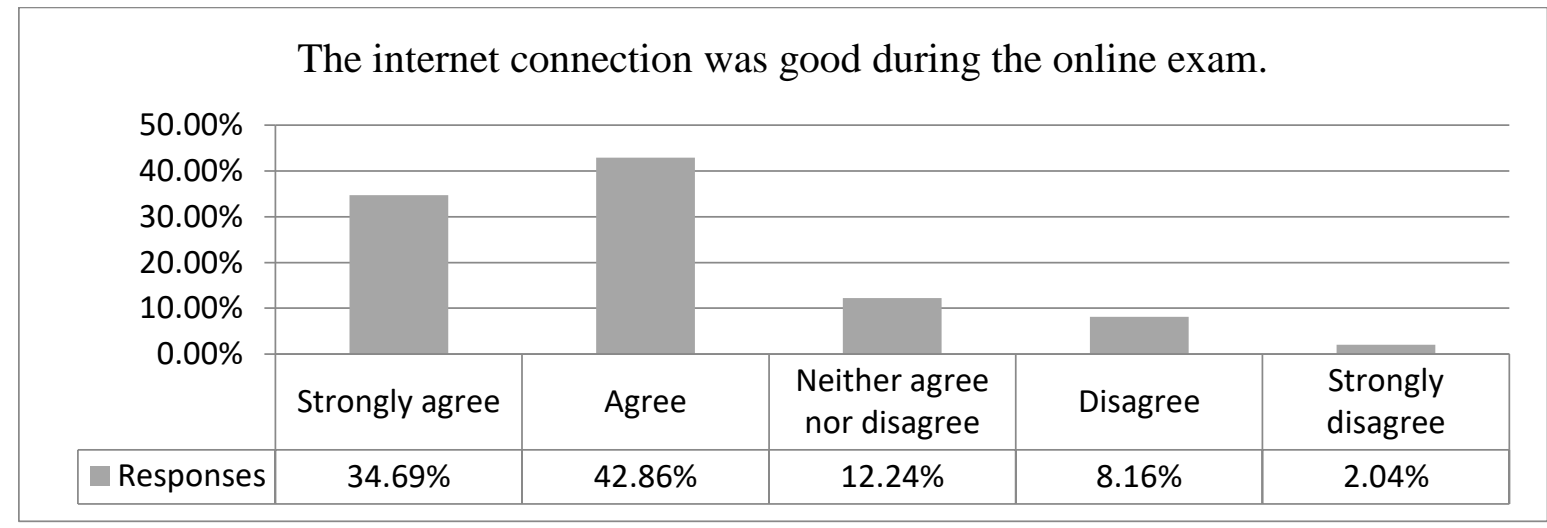

Figure 2. Availability of the Online Exam

Regarding availability, students were asked about one of the essential elements in the online exam, which is the internet connection. Remarkably, $77.38 \%$ of the students had a good connection during the online exam (see Figure 2 ). Only $10.20 \%$ of the students identified poor internet connection as a challenge, and $12.24 \%$ did not clarify the stability of their internet connection (see Figure 2). Broadly speaking, the findings of Figure 2 highlight that the students mostly had a stable and available internet connection and as can be seen in Figures 1 and 2, there is not a significant difference in students' experience towards accessibility and availability. 


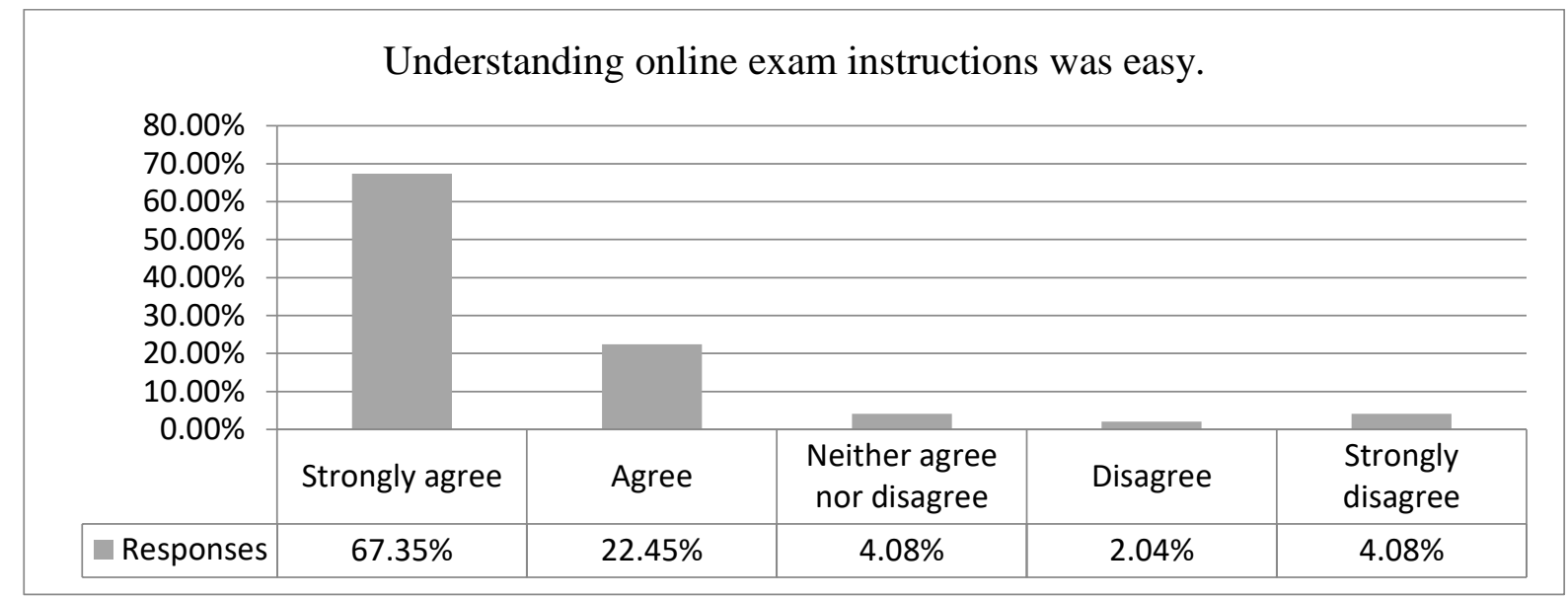

Figure 3. Clarity of the Online Exam Instructions (Ease)

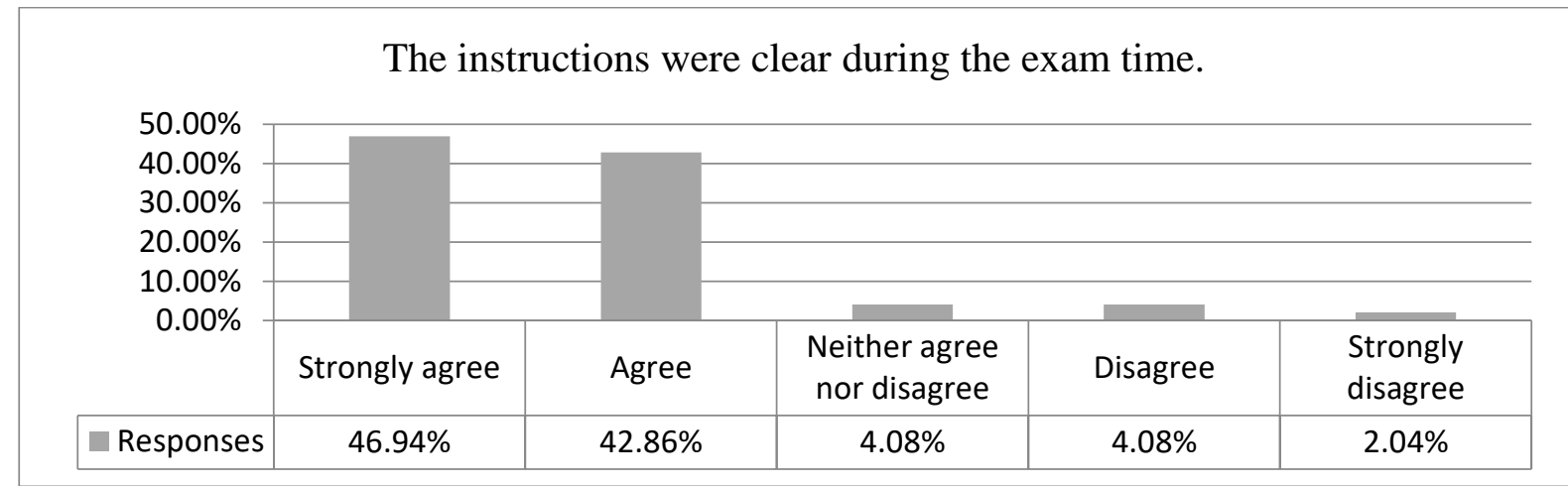

Figure 4. Clarity of the Online Exam Instructions

Concerning online exam instructions, almost $89 \%$ of the students agreed that understanding the online exam instructions was easy (see Figure 3). Moreover, nearly $86 \%$ of the students reported that the rules had been clear during the exam time (see Figure 4). These results indicate that the online exam was well-designed in terms of the clarity of instructions.

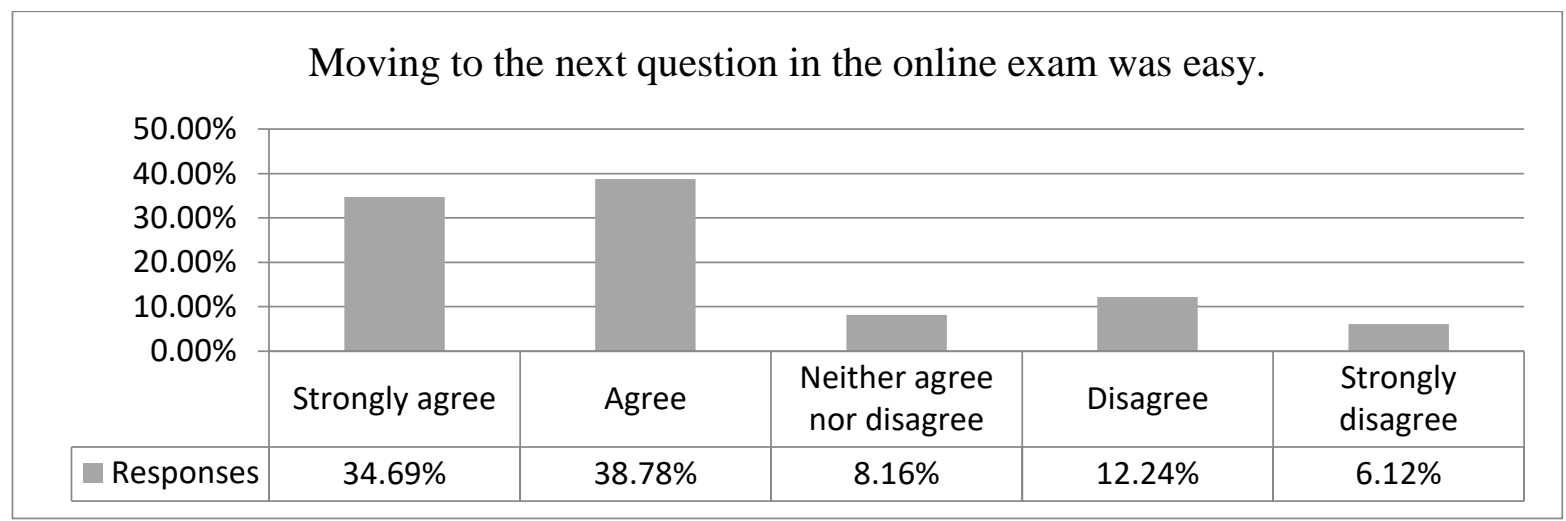

Figure 5. Mode of Online Exam Delivery (sequence)

In response to the mode of delivery in the online exam, almost $74 \%$ of students reported that the process of moving to each subsequent question in the online exam was easy (see Figure 5), which indicates that the majority of students did not face issues with the mode of delivery in the online exam. However, around $18 \%$ of students disagreed that moving from one question to another was a smooth process (see Figure 5). 


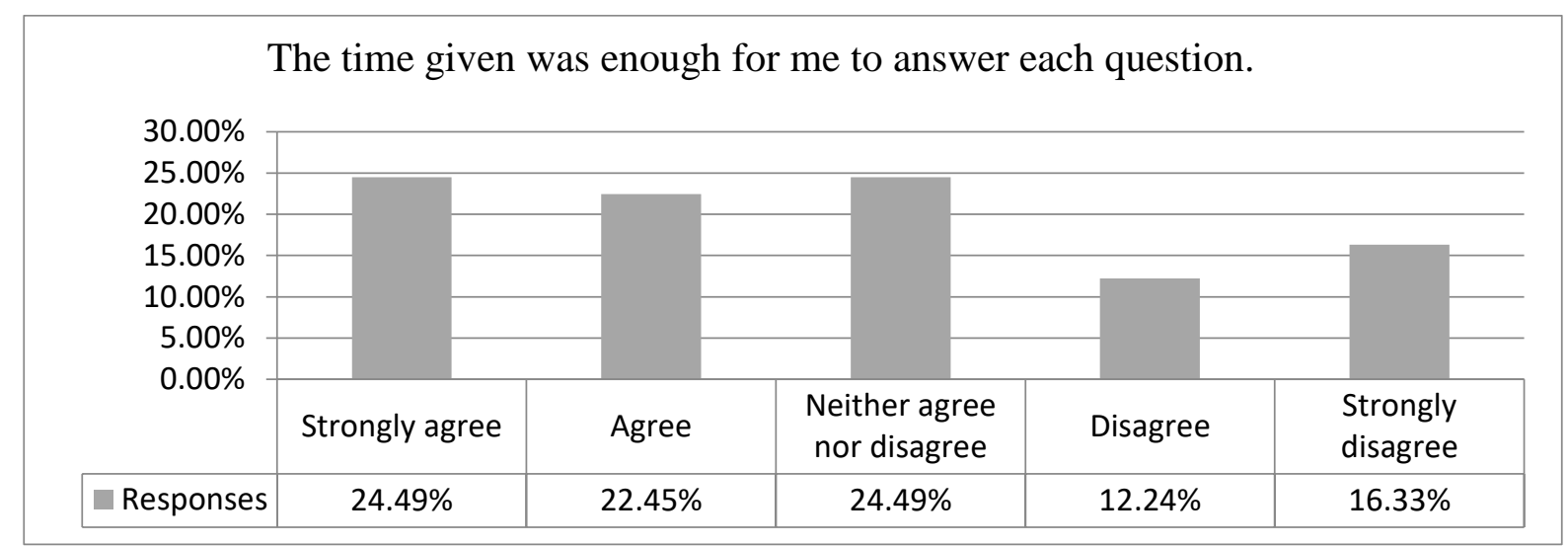

Figure 6. Mode of Online Exam Delivery (time)

Interestingly, as shown in Figure 6, an equivalent number of students (24.49\%) strongly agreed and $24.49 \%$ were neutral regarding the time limit being sufficient for answering each question in the online exam. The results further revealed no significant difference between students who strongly disagreed (16\%) and those who agreed (22\%) that the time given was sufficient for answering the questions (see Figure 6), which could suggest that whether the time given was sufficient for answering each question depended on students' familiarity with the timed mode of delivery.

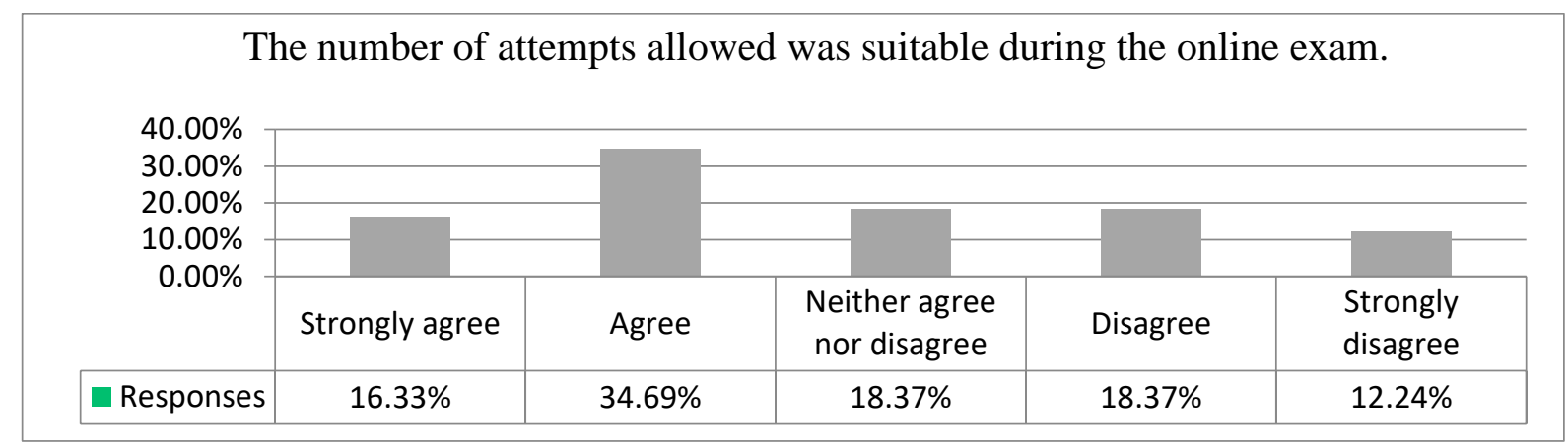

Figure 7. Mode of Online Exam Delivery (attempts)

The results indicated that almost $51 \%$ of students found the number of attempts permitted during the online exam convenient (see Figure 7) and the results of the survey further demonstrated an equivalent response of $49 \%$ of students who either disagreed or were neutral towards the suitability of the number of attempts permitted (see Figure 7). Thus, these results can be interpreted to indicate that the number of attempts allowed in the online exam was not convenient for those students.

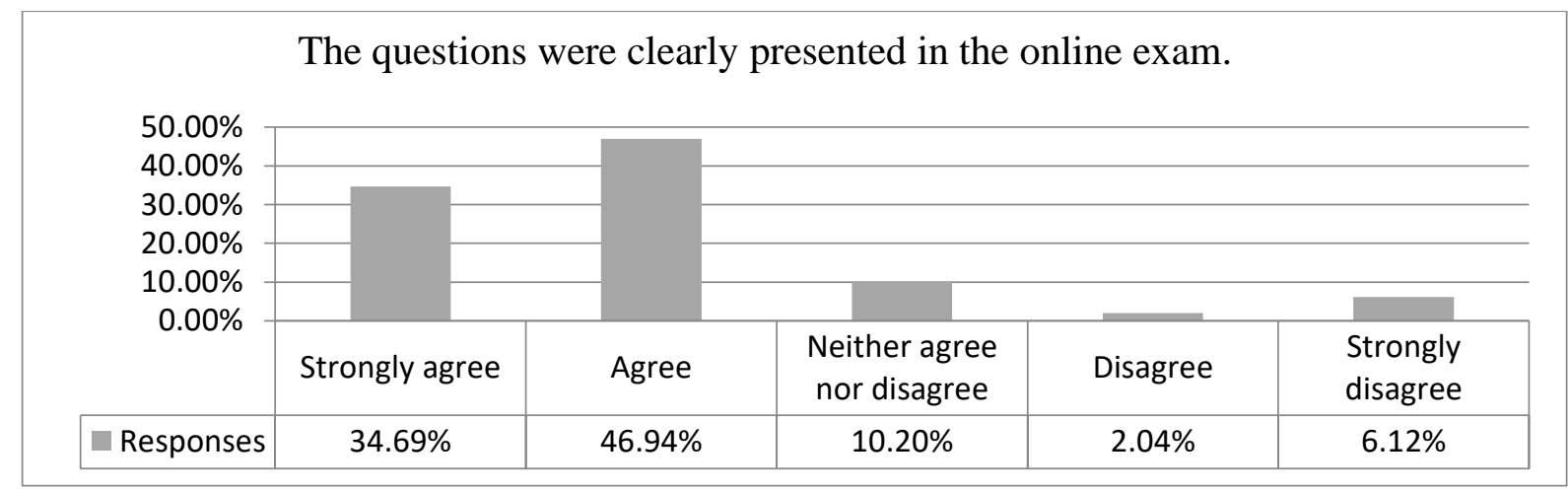

Figure 8. Mode of Online Exam Delivery (presentation)

Finally, approximately $82 \%$ of students agreed that the questions were clearly presented in their online exam (see Figure 8 ). In contrast, around $8 \%$ of students felt that the presentation of questions was unclear (see Figure 8 ), which could be due to these students facing some technical issues during the online exam. 
The current study found surprising insights into students' experience with online exam accessibility and availability. For example, the findings of the present study show that only $10.20 \%$ of the students faced issues in terms of internet connection. In contrast to that finding, a recent study reported that internet connection was one of the biggest challenges for students in the online exam, finding that $77 \%$ of the students faced problems in internet connectivity (Bisht, Jasola, and Bisht, 2020). However, it is worth mentioning that the population of Bisht Jasola, and Bishts' study were students from India. Hence, this remarkable difference in the percentages may be due in part to students' geographical location. The variety in different geographical locations and areas could account for the surprising difference in how problematic internet connection could be. As Jeddah is the second-largest city in Saudi Arabia, the infrastructure is high, whereas students from other cities and towns may have a different experience. Thus, the International Test Commission (2006) recommended that test developers should design a test that works with low-speed internet connection. Also, a significant result that emerged from the qualitative data was the effortless accessibility and availability in the online exam. As explained by a student in the interview, the reason for having a positive experience in terms of accessibility and availability was that she was "well-prepared" for the online environment by "buying a personal laptop and acquiring good internet connection." As a result, it can be argued that the sudden shift to online learning encouraged students to be independent and responsible; however, some students may still face obstacles in terms of accessibility due to financial costs (Isbell \& Kremmel, 2020).

As for the clarity of the online exam, the results show that students were satisfied with the online exam instructions. In fact, in the interviews, one student reported that the use of "simple English words" in the instructions, during the examination process, made the instructions easier to understand, while the other student reported that the guidelines for the online exam, which had been emailed to all students before the online exam, "eased the examination process." This indicates that familiarising students with the online exam rules via comprehensible guidelines before the exam time can make students feel more confident about what they will have to do during the online exam.

Regarding the mode of online exam delivery, the variety of results indicate that students' ability to cope with a time restriction mode in online exams may depend on students' familiarity with being time restricted (see Figure 6). As reported in the literature, the struggle is often due to students' unfamiliarity or inexperience with certain delivery mode features (Brunfaut, Harding, \& Battyb, 2018). Accordingly, students' ability to perform while being timed could be improved through practice. This suggests implementing an online mock exam where students can practice the time restriction mode. In addition, the varied data call attention to the test design in setting a convenient time restriction for online exams (Stack et al., 2020), which is suitable for students with different levels of digital literacy. Digital literacy refers to a person's ability to understand and evaluate information presented via online platforms (Mohammadyari \& Singh, 2015). Moreover, the results of this study indicate that Blackboard's clear presentation of questions caters to students' preferences about question delivery. In fact, the two students in the interview used the word 'easy' to describe their experience with Blackboards' online exam delivery.

\section{Conclusion}

The present study was designed to explore EFL students' perceptions of an online English achievement exam. In conclusion, the overall findings revealed that the availability and accessibility, clarity of instructions, and delivery mode in the online exam played a significant role in students' positive feedback. This positive feedback, as highlighted in the survey, is probably due to the fact that during the shift to online learning, students had no other choice than to acquire the internet connection tools necessary to access the online exam. Furthermore, according to the students' responses from the interviews, the clarity of exam instructions and mode of delivery in the online English exam significantly improved students' perceptions towards online exams. These findings highlight several implications for developing online exam delivery. First, test designers should consider using flexible software for the online exam that does not require a high-speed internet connection. Second, providing students with a guideline for the rules and instructions before the online exam. Third, it is suggested to improve students' digital literacy by practicing through an online mock exam. Finally, it is recommended for test designers to use an online assessment tool with a simple and direct presentation of the online exam delivery, such as Blackboard. However, due to the COVID-19 mandated social restrictions, the current study was limited to a small number of interviewees; therefore, further research might interview more participants to explore a wide range of perspectives and reveal a deeper understanding of the issue at hand. Also, further studies on the current topic are strongly recommended to investigate the required shift to online assessments.

Funding: This research received no external funding. This article was fully sponsored by the authors.

Acknowledgments: The authors would like to thank all the participants for their time and effort.

Conflicts of Interest: The authors declare no conflict of interest. 


\section{References}

[1] Alharbi, A. S., \& Meccawy, Z. (2020). Introducing Socrative as a Tool for Formative Assessment in Saudi EFL Classrooms. Arab World English Journal, 11(3), 372-384. https://doi.org/10.24093/awej/vol11no3.23

[2] Alshehri, A., Rutter, M. J., \& Smith, S. (2019). An implementation of the UTAUT model for understanding Students' perceptions of learning management systems: A study within tertiary institutions in Saudi Arabia. International Journal of Distance Education Technologies (IJDET), 17(3), 1-24. https://doi.org/10.4018/IJDET.2019070101

[3] Bisht, R. K., Jasola, S., \& Bisht, I. P. (2020). Acceptability and challenges of online higher education in the era of COVID-19: A study of students' perspective. Asian Education and Development Studies. https://doi.org/10.1108/AEDS-05-2020-0119

[4] Braun, V., \& Clarke, V. (2006). Using thematic analysis in psychology. Qualitative Research in Psychology, 3(2), 77-101. https://doi.org/10.1191/1478088706qp063oa

[5] Brunfaut, T., Harding, L., \& Batty, A. O. (2018). Going online: The effect of mode of delivery on performances and perceptions on an English L2 writing test suite. Assessing Writing, 36, 3-18. https://doi.org/10.1016/j.asw.2018.02.003

[6] Butler-Henderson, K., \& Crawford, J. (2020). A systematic review of online examinations: A pedagogical innovation for scalable authentication and integrity. Computers \& Education, 159(17), 1-12. https://doi.org/10.1016/j.compedu.2020.104024

[7] Dornyei, Z. (2007). Research Methods in Applied linguistics: Quantitative, Qualitative, and Mixed Methodologies. New York: Oxford University Press.

[8] Frankl, G., \& Schratt-Bitter, S. (2012). Online Exams: Practical Implications and Future Directions. Proceedings of the European Conference on E-Learning, 158-164.

[9] Fulcher, G. (2010). Practical Language Testing. London: Hodder Education

[10] International Language Standards: Cambridge English. Retrieved December 13, 2020, from https://www.cambridgeenglish.org/exams-andtests/cefr/

[11] IBM Corp. Released 2012. IBM SPSS Statistics for Windows, Version 21.0. Armonk, NY: IBM Corp.

[12] International Test Commission. (2006). International guidelines on computer-based and internet-delivered testing. International Journal of Testing, 6(2), 143-171. https://doi.org/10.1207/s15327574ijt0602 4

[13] Isbell, D. R., \& Kremmel, B. (2020). Test review: Current options in at-home language proficiency tests for making high-stakes decisions. Language Testing, 37(4), 600-619. https://doi.org/10.1177/0265532220943483

[14] Layali, K., \& Al-Shlowiy, A. (2020). Students' perceptions of e-learning for ESL/EFL in Saudi universities at time of Coronavirus: A literature review. Indonesian EFL Journal (IEFL), 6(2), 97-108.

[15] Matthíasdóttir, Á., \& Arnalds, H. (2016). E-assessment: students' point of view. Paper presented at the Proceedings of the 17th International Conference on Computer Systems and Technologies 2016, Palermo, Italy. https://doi.org/10.1145/2983468.2983497

[16] Mohammadyari, S., \& Singh, H. (2015). Understanding the effect of e-learning on individual performance: The role of digital literacy. Computers \& Education, 82, 11-25. https://doi.org/10.1016/j.compedu.2014.10.025

[17] Özden, M. Y., Erturk, I., Sanli, R. (2004). Students' perception of online assessment: A case study. Journal of Distance Education, 19(2), 77-92.

[18] Pearson, E. J., \& Koppi, T. (2002). Inclusion and online learning opportunities: designing for accessibility. ALT-J, 10(2), $17-28$. https://doi.org/10.1080/0968776020100203

[19] Rahim, A. F. A. (2020). Guidelines for Online Assessment in Emergency Remote Teaching during the COVID-19 Pandemic. Education in Medicine Journal, 12(2), 59-68. https://doi.org/10.21315/eimj2020.12.2.6

[20] Salmon, G. (2013). E-tivities: The key to Active Online Learning (2nd ed.). London and New York: Routledge

[21] Sarrayrih, M. A., \& llyas, M. (2013). Challenges of online exam, performances and problems for online university exam. International Journal of Computer Science Issues (IJCSI), 10(1), 439-443.

[22] Sewell, J., Frith, K. H., \& Colvin, M. M. (2010). Online assessment strategies: A primer. Journal of Online Learning and Teaching, 6(1), 297305. Retrieved from https://jolt.merlot.org/vol6no1/sewell 0310.htm

[23] Shraim, K. (2019). Online examination practices in higher education institutions: learners' perspectives. Turkish Online Journal of Distance Education, 20(4), 185-196. https://doi.org/10.17718/tojde.640588

[24] Stack, A., Boitshwarelo, B., Reedy, A., Billany, T., Reedy, H., Sharma, R., \& Vemuri, J. (2020). Investigating online tests practices of university staff using data from a learning management system. Australasian Journal of Educational Technology, 36(4), 72-81. https://doi.org/10.14742/ajet.4975

[25] Yildiz, M. N., \& Keengwe, J. (Eds.). (2016). Handbook of Research on Media Literacy in the Digital Age. Hershey PA, USA: IGI Global.

[26] Yoshino, A., Shigemura, J., Kobayashi, Y., Nomura, S., Shishikura, K., Den, R., Wakisaka, H., Kamata, S., \& Ashida, H. (2001). Telepsychiatry: assessment of televideo psychiatric interview reliability with present-and next-generation internet infrastructures. Acta Psychiatrica Scandinavica, 104(3), 223-226. https://doi.org/10.1034/j.1600-0447.2001.00236.x 